\title{
A Digital Tectonic Activity Map of the Earth
}

\section{Paul Lowman, Penny Masuoka, Brian Montgomery, Jay O'Leary, Demetra Salisbury, and Jacob Yates}

17 Mar. 99

The subject of neotectonics, covering the structures and structural activity of the last 5 million years (i.e., post-Miocene) is a well-recognized field, including "active tectonics," focussed on the last 500,000 years in a 1986 National Research Council report of that title. However, there is a cartographic gap between tectonic maps, generally showing all features regardless of age, and maps of current seismic or volcanic activity. We have compiled a map intended to bridge this gap, using modern data bases and computer-aided cartographic techniques.

The maps presented here are conceptually descended from an earlier map showing tectonic and volcanic activity of the last one million years (Lowman, 1981,1982). Drawn by hand with the National Geographic Society's 1975 "The Physical World" map as a base, the 1981 map in various revisions has been widely reproduced in textbooks (e.g.,Siegal and Gillespie,1980) and various technical publications (e.g., McKelvey, 1986). However, two decades of progress call for a completely new map that can take advantage of new knowledge and cartographic techniques. The digital tectonic activity map (DTM), presented in shaded relief (Fig. 1) and schematic (Fig. 2) versions, is the result.

The DTM is intended to show tectonism and volcanism of the last one million years, a period long enough to be representative of global activity, but short enough that features such as fault scarps and volcanos are still geomorphically recognizable.

\section{Data Sources and Cartographic Methods}

The DTM is based on a wide range of sources, summarized in Table 1. The most important is the digital elevation model, used to construct a shaded relief map. The bathymetry is largely from satellite altimetry, specifically the marine gravity compilations by Smith and Sandwell (1996). The shaded relief map was designed to match the new National Geographic Society world physical map (1992), although drawn independently, from the digital elevation model. The Robinson Projection is used instead of the earlier Van der Grinten one. Although neither conformal nor equal-area, the Robinson 
Projection provides a reasonable compromise and retains useful detail at high latitudes. Like the National Geographic Society map, the DTM is centered on the prime meridian to avoid splitting major land masses.

The DTM shaded relief map is an objective compilation, unlike the 1975 National Geographic Van der Grinten map, an artist's rendition drawing heavily on the classic Tharp-Heezen ocean floor maps. The Global Tectonic Activity Map of the Earth (GTA) was drawn by hand with the shaded relief map as a base. Delineation of active tectonic features, such as the mid-ocean ridges, follows the bathymetry or topography as closely as possible, taking into account the distribution of seismic activity.

A series of seismic activity maps was compiled, both equatorial and polar (Figs.3,4,5), the latter also showing volcanism of the last one million years. Since development in the 1960s of the World Wide Standardized Seismographic Network (WWSSN) to monitor nuclear tests (Bolt, 1976), our knowledge of global seismicity has expanded enormously. A Robinson Projection map of 358,214 epicenters of all magnitudes, between 1963 and 1998, was compiled. Although bringing out many little-known active areas, areas such as western Europe were saturated with non-tectonic events such as quarry blasts. This problem has long challenged those involved in nuclear test monitoring ( Hennet et al., 1996). Stump et al. (1994) cite a figure of 10,000 man-made seismic events per day in the United States. We therefore compiled equatorial and polar seismicity maps showing only events with magnitudes (chiefly $\mathrm{mb}$ ) over 3.5. According to Hennet et al., a magnitude 4 corresponds roughly to a 1 kiloton explosion. Most industrial blasts are much less powerful than this, generally below 50 tons (Stump et al., 1994).

Many interesting zones of seismic activity are in the oceans, as off the coast of Norway. To see if these events might be offshore petroleum prospecting blasts, an epicenter map showing only events less than magnitude 3.5 was compiled. Most of the events in this particular area were thus eliminated. Furthermore, there were virtually no events in areas of intense petroleum exploration activity, such as the Grand Banks or the Gulf of Mexico. We conclude, therefore, that most of the events shown on Fig. 3 are natural, outside areas of known nuclear testing.

No effort has been made to screen nuclear explosions from the epicenter map. Even relatively small explosions, in the $30-50$ kiloton range, can produce $\mathrm{mb}$ events with values well over 3.5 , and some of those on the 
map are undoubtedly nuclear tests. The isolated event in southern Algeria, and the cluster on Novaya Zemlya, are obvious examples.

Areas of volcanic activity include both the mid-ocean ridges, presumably the site of recent fissure eruptions even though few such have been observed (e.g., in Iceland), and features of the central eruptive type. The latter are highly generalized, with any one symbol generally representing several volcanos. The primary data source was the Smithsonian Institution's compilation, and Simkin and Siebert (1994), supplemented by geologic maps used with the aid of orbital photography (Lowman, 1982). It was assumed that in most areas, volcanos remain recognizable for roughly one million years after their last activity. Any feature that still looks like a volcano has probably been active within this period. Similarly, a fault scarp (as distinct from a fault-line scarp, formed by differential erosion) that is still distinct has also been active in the last million years.

Sea-floor spreading rates were taken from the NUVEL-1 model of DeMets et al. (1990), based on the spacing of dated magnetic anomalies. This approach, used by Minster et al. (1974) and Minster and Jordan (1978), has been supported by other evidence, in particular space geodesy. A Robinson Projection map of Very Long Baseline Interferometry (VLBI) site motion vectors has been compiled, showing directions and approximate magnitudes. Methods and results of this and other space geodesy programs have been summarized in the volume edited by Smith and Turcotte (1993). Although not presented here, a Robinson Projection version of the simplified World Stress Map (Zoback, 1992) has been compiled. An interesting discrepancy has been noticed between the World Stress Map and plate motions in western Europe. When plotted on the basis of NUVEL-1, with the Pacific plate held stationary, the station vectors appear to trend uniformly to the northeast. However, a similar compilation with the North American plate held stationary shows the European vectors trending to the southeast (Ryan et al., 1993). The World Stress Map shows clearly that actual crustal motions in western Europe must be in this direction, i.e., to the southeast, presumably as the result of ridge push from the Mid-Atlantic Ridge (Zoback, 1992). The map shown here is presented primarily as a demonstration of possible anomalies brought out by the digital tectonic activity map.

Major plates have been labeled using accepted nomenclature. However, as will be discussed, the DTM is not a "plate map" in that plate boundaries in, for example, Asia are extremely broad and diffuse. Oceanic 
plate boundaries, in contrast, are easily drawn on the basis of topography and seismic activity. The extent of continental crust, on the Global Tectonic Activity Map, was drawn on the basis of bathymetry supplemented by other geophysical, geological, or geochemical data. The Rockall Plateau, for example, has been known for decades to be continental crust. However, the Rockall Trough, despite its abyssal depth, is now considered continental in composition on the basis of reflection profiling (Hauser et al., 1995). The Faeroe Plateau, though surfaced with basalt, has been found by geochemical studies to be underlain at depth by sialic crust (Gariepy et al., 1983).

The DTM and GTA were created with commercially available software. $\mathrm{PCI}$, an image processing program, was used to generate the shaded relief map from the digital elevation data previously described. After the GTA was drawn by hand, it was digitized, converting each feature to a point or line. Arcview, a geographic information system, was used to integrate the newly created raster and vector files. The integrated format was then imported into Adobe Photoshop. Photoshop permits manipulation of all image formats, and was used for combining and manipulating text, line features, raster files, and the geologic interpretation (the GTA) for the final cartographic output.

Preliminary Interpretations of the DTM and GTA

The purpose of this paper is primarily to simply present the maps, their data sources, and the methods used to compile them. However, a few major questions are immediately suggested by even a simple inspection of the maps, including the following.

Can the Earth's crust be realistically described in terms of a finite number of plates?

A fundamental tenet of plate tectonic theory is that most tectonic activity is the result of interaction among rigid and relatively inactive lithospheric plates, 12 in the widely used NUVEL-1 model (Stein, 1993). The NUVEL-1 model has been tested repeatedly by space geodesy, and in general has been found to predict site motions in direction and magnitude reasonably well. Significant exceptions have been found even in classic plate boundaries, such as the South America/Pacific plate area, where the Arequipa site has been found to share in the eastward motion of the Pacific plate (Robaudo and Harrison, 1993). However, these anomalies are explainable in terms of plate theory. 
Viewing the Earth as a whole, on the other hand, we see clearly that large areas, especially on continents, can not be assigned to discrete plates. The diffuse nature of continental plate boundaries has been noted by many authors, such as Stein (1993). Nevertheless, the broad zone of intense seismic activity in, for example, south central Asia emphasizes the artificiality of plate maps showing the Eurasian plate as extending from Iceland to Indonesia. The DTM is thus presented as a much more realistic view of global tectonism. Are old "inactive" orogenic belts truly inactive?

Two classic folded mountain belts, the Appalachians and the Urals, are generally believed to have been formed by continental collisions in the late Paleozoic, after which they have been essentially inactive except for vertical movements. The World Stress Map appears to confirm such interpretations, in that as pointed out by Zoback (1992) "Residual stresses from past orogenic events do not appear to contribute in any substantial way to the modern stress field." However, the Appalachians are shown as active on the basis of seismicity, explained by Sykes (1978) as resulting from movement on the landward extension of oceanic fracture zones. As shown in Fig. 3, Appalachian seismicity appears to parallel the major Paleozoic structural trends, both fold axes and thrust faults. Seismicity is not as well defined in the Urals, but Russian geodetic and geological evidence (Trifunov, 1983) shows clearly that they are still (or again?) undergoing faulting and uplift, although utterly isolated from any possible transverse fracture zone.

Much older fold belts, such as the Proterozoic Labrador Trough, appear truly inactive. However, the DTM suggests that fold belts may remain active much longer than previously realized. This possibility should be tested by GPS surveys and further in situ stress measurements of the sort used for the World Stress Map.

\section{What causes seismic activity in the Alpine fold belt?}

The intense seismicity of the western Tethyan fold belt, or Alpine belt, is dramatically shown on the epicenter map. This seismicity is generally explained in geology texts as the result of continental or plate collisions, specifically between the African and Eurasian plates. However, simple examination of the DTM and GTA suggests that both such plates are rotating in the same general direction, counter-clockwise away from the Mid-Atlantic Ridge. Such as interpretation can be justifiably described as simplistic, but all numerical plate models, such as NUVEL-1, show the African and Eurasian 
plates as the slowest-moving of all major plates. The inverse relation between plate velocity and relative continental crust area was first noticed by Minster et al. (1974). The African plate has in fact been described by Burke and Wilson (1972) as fixed over the mantle for the past 25 million years on the basis of the absence of hot spot trails.

The situation is thus something of a paradox: one of the most seismically active areas on the planet is located between two plates that are hardly moving. Can this be caused by "residual stresses from past orogenic events" as described by Zoback (1992) in relation to the World Stress Map? Or is another mechanism at work, such as "extensional collapse of orogens" (Dewey, 1988)? The DTM provides no obvious answer to these questions, but it at least highlights the existence of a tectonic anomaly.

\section{Summary}

The combination of vastly increased knowledge of the Earth, from space-related and conventional studies, with new data-handling techniques, has produced a new view of the Earth's tectonic and volcanic activity. This new view is generally compatible with plate tectonic theory, but is a much more complex picture than the one familiar to all geology students for the last two decades. It is also a more realistic one, intended to show actual tectonically active features, subject to scale and cartographic limitations, rather than the idealized ones of plate maps.

These maps should be of value not only in geologic education, but in natural hazard programs, geophysical exploration, and perhaps in political problems such as enforcement of the Comprehensive Test Ban Treaty. Their greatest scientific value, however, may be in raising awareness of tectonic questions not answered by now-conventional plate tectonic theory.

\section{Acknowledgements}

This map was produced with support from the Goddard Space Flight Center Director's Discretionary Fund, Task 97-51. We thank the former Center Director, Joe Rothenberg, and Jerry Soffen for their support. Data from and discussions with the GSFC Space Geodesy Branch, specifically Chopo Ma, Jim Ryan, Tom Clark, and Karen Baver were essential for the VLBI station velocity map.

Commercial software used is named for identification, and does not imply endorsement by the U.S. government. 


\section{References}

Bolt, B., Nuclear Explosions and Earthquakes: the Parted Veil, W.H. Freeman, San Francisco, 309 p., 1976.

Burke, $\mathrm{K}$, and J. T. Wilson, Is the African plate stationary? Nature, 239, 3887389, 1972.

DeMets, C., R.G. Gordon, D.F. Argus, and S. Stein, Current plate motions, Geophys. J. Int., 101, 425, 1990.

Dewey, J.F., Extensional collapse of orogens, Tectonics, 7, 1123-1139, 1988.

Hauser, F.,B.M. O'Reilly, A.W. Brian Jacob, P.M. Shannon, J. Makris, and U. Vogt, The crustal structure of the Rockall Trough: Differential stretching without underplating, J. Geophys. Res.100, B3, 4097-4116, 1995.

Hennet, C.B., G.E. van der Vink, P.G. Richards, V.V. Adushkin, Y.F. Kopnichev, and R. Geary, Multi-use seismic stations offer strong deterrent to clandestine nuclear weapons testing, Eos Trans. AGU, 77, 289, 1996.

Gariepy, C., J. Ludden, and C. Brooks, Isotopic and trace element constraints on the genesis of the Faeroe lava pile, Earth Planet.Sci. Lett., 63, 257-272, 1983.

Lowman, P.D.,Jr., A global tectonic activity map, Bull. Int. Assoc. of Engineering Geology, 23, 37, 1981.

Lowman, P.D.Jr., A more realistic view of global tectonism, J. Geological Education, 30, 97, 1982.

McKelvey, V.E., Subsea Mineral Resources, U.S. Geological Survey Bull. 1689A, 106 p., 1986.

Minster, J.B.,T.H. Jordan, P. Molnar, and E.Haines, Numerical modeling of instantaneous plate tectonics, Geophys. J. Roy. Astron. Soc., 36, 541-576, 1974. Minster, J.B., and T.H.Jordan, Present-day plate motion, J. Geophys. Res., 83, 5331-5354, 1978.

Robaudo, S., and C.G.A. Harrison, Plate tectonics from SLR and VLBI global data, in Contributions of Space Geodesy to Geodynamics, D.E. Smith and D.L. Turcotte (Editors),pp, 51-71, v. 23, Geodynamics Series, 1993.

Ryan, J.W., T.A. Clark, C. Ma, D. Gordon, D.S. Caprette, and W. E. Himwich, Global scale tectonic plate motion measured with CDP VLBI, in Contributions of Space Geodesy, to Geodynamics: Crustal Dynamics, D. E. Smith and D.L. Turcotte (Editors), pp. 37-49, American Geophysical Union, 1993.

Siegal, B.S., and A.R. Gillespie (Editors), Remote Sensing in Geology, John Wiley, New York, 702 p., 1980. 
Simkin, T., and L. Siebert, Volcanos of the World, 2d ed., Smithsonian Institution, Geoscience Press, Tucson, 1994.

Smith, D.E., and D.L. Turcotte (Editors), Contributions of Space Geodesy to Geodynamics, v. 23, Geodynamics Series, American Geophysical Union, 1993. Smith, W.H.F., and D. T. Sandwell, Global sea floor topography from satellite altimetry and ship depth soundings, Science, 277, 1956-1962, 1997.

Stein, S., Space geodesy and plate motions, in Contributions of Space Geodesy to Geodynamics, D.E. Smith and D.L. Turcotte (Editors), v. 23, Geodynamics Series, American Geophysical Union, 1993.

Stump, B.W., F. Riviere-Barbier, I. Chernoby, and K. Koch, Monitoring a test ban treaty presents scientific challenges, Eos Trans. AGU, 75, 265, 1994.

Sykes, L.R., Intraplate seismicity, reactivation of pre-existing zones of weakness, alkaline magmatism, and other tectonism post-dating continental fragmentation, Rev. Geophys. Space Physics, 16, 621-688, 1978.

Trifunov,Y.P., The geological-geomorphological records of Recent tectonic movements in the Urals and Transurals, Recent Crustal Movements, No. 1, International Geophyhsical Committee of the Presidium of the Academy of Sciences, USSR, 1983.

Zoback, M.L., First- and second-order patterns of stress in the lithosphere: The World Stress Map Project, J. Geophys. Res.,97, 11,703, 1992.

\section{Figure Captions}

Fig. 1 Digital tectonic activity map of the Earth

Fig. 2 Global tectonic activity map of the Earth

Fig. 3 Global seismicity, 1963-1998

Fig. 4 Seismic activity and volcanism, northern hemisphere; map symbols same as Fig. 2.

Fig. 5 Seismic activity and volcanism, southern hemisphere; map symbols same as Fig. 2

Fig. 6 Horizontal VLBI station velocities, $\mathrm{mm} /$ year. Legend staggered at left because of typographic limitations.

Table 1 Sources of information for the Digital Tectonic Activity Map. 


\section{Base-map (all projections);}

The digital elevation model (DEM) obtained from the National Geophysical Data Center (NGDC). It was converted to Robinson and Polar stereographic projections for the digital tectonic activity map project using PCI software. The original data set, called TerrainBase by NGDC, can be downloaded from this site: http://www.ngdc.noaa.gov/seg/topo/topo.shtml

\section{Seismic Data: (358,214 events)}

Seismicity Catalogs CD-Rom (double) set

-Vol. I: North America, 1492-1996 AD

-Vol. 2: Global and Regional, 2150 BC-1996 AD

compilation of seismic data courtesy of:

-NOAA's National Geophysical Data Center (NGDC), Boulder, CO, USA, \& -USGS's National Earthquake Information Center, Golden Colorado, USA. contact: Lowell Whiteside

\section{VLBIData: (127 events)}

VLBI Horizontal Velocities (1997 data) \& Site Locations (1997 data) downloaded via http://lupus.gsfc.nasa.gov/vlbi.html

This research has made use of NASA Goddard Space Flight Center's VLBI 1997 data, via the Space Geodesy Branch (Code 926).

\section{Current Reference:}

Ma, C., and J. W. Ryan, "NASA Space Geodesy Program - GSFC DATA Analysis - 1998, VLBI Geodetic Results 1979-1998", August, 1998.

Volcanic Data: (1488 events)

Smithsonian Institution's Global Volcanism Program:

-Holocene Volcano Basic Data -http://www.volcano.si.edu/gvp/volcdata/

World Stress Map:

Reference: Zoback, M.L., J. Geophys. Res., 97, 11,703, 1992. 

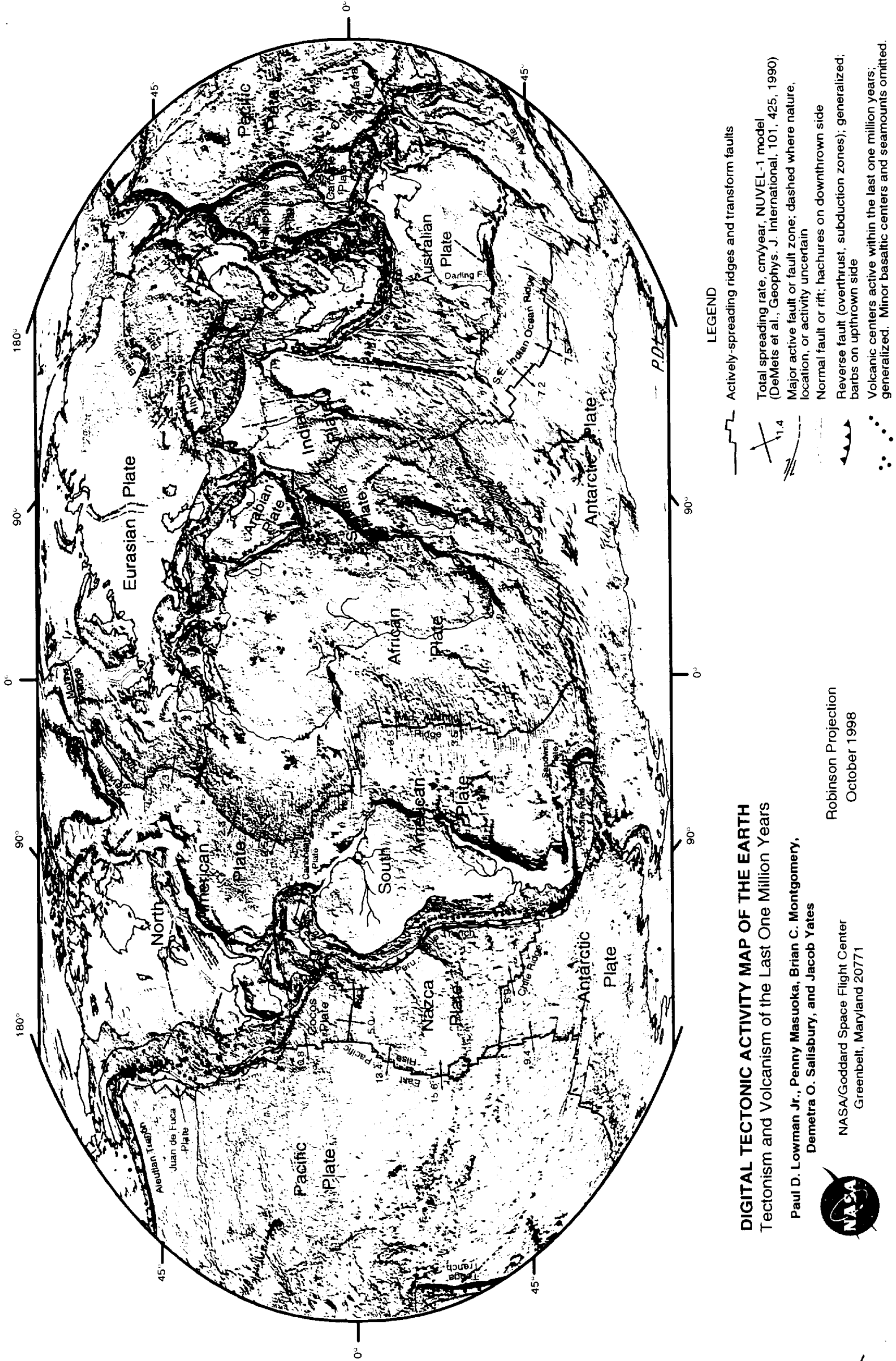


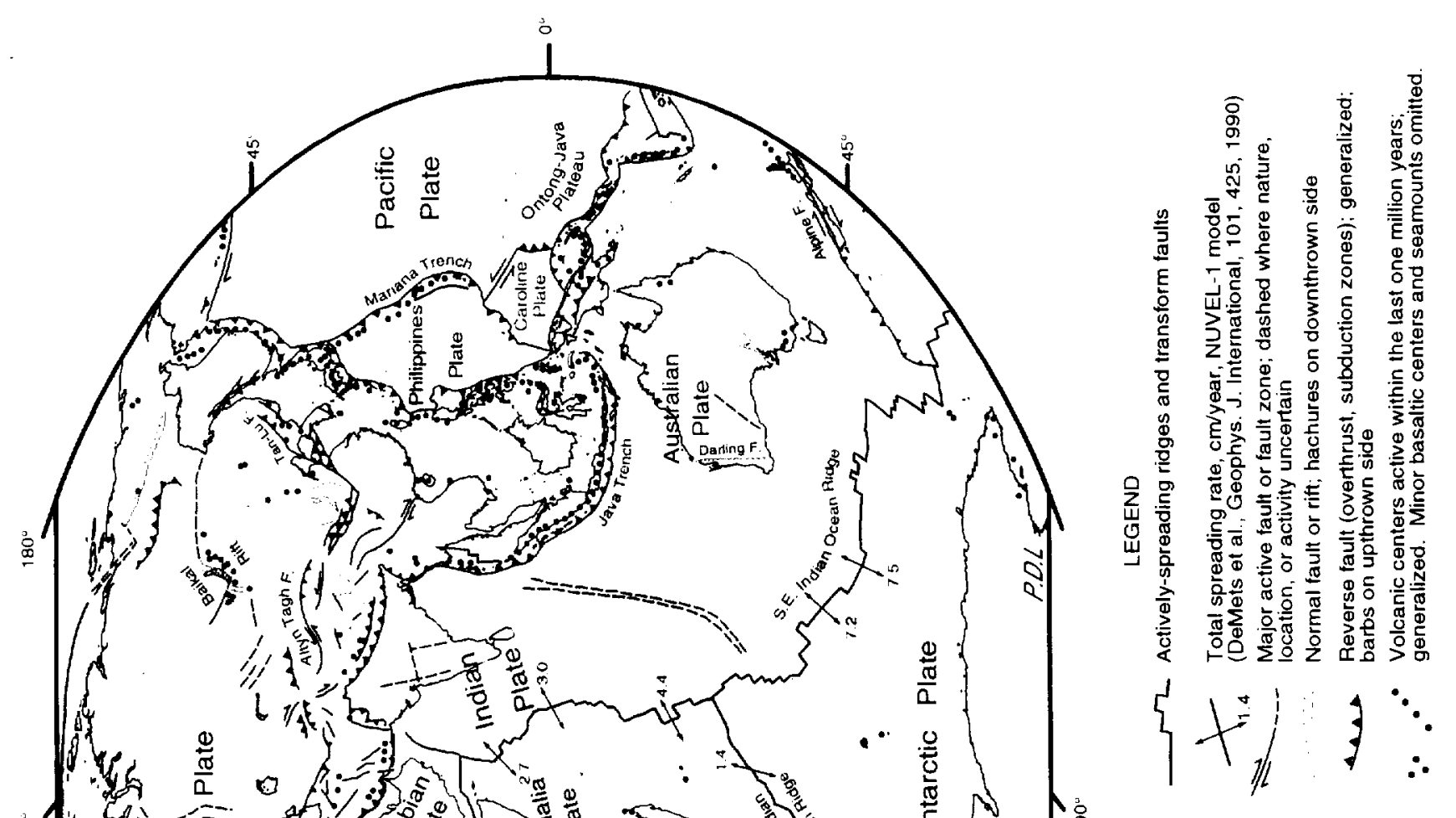




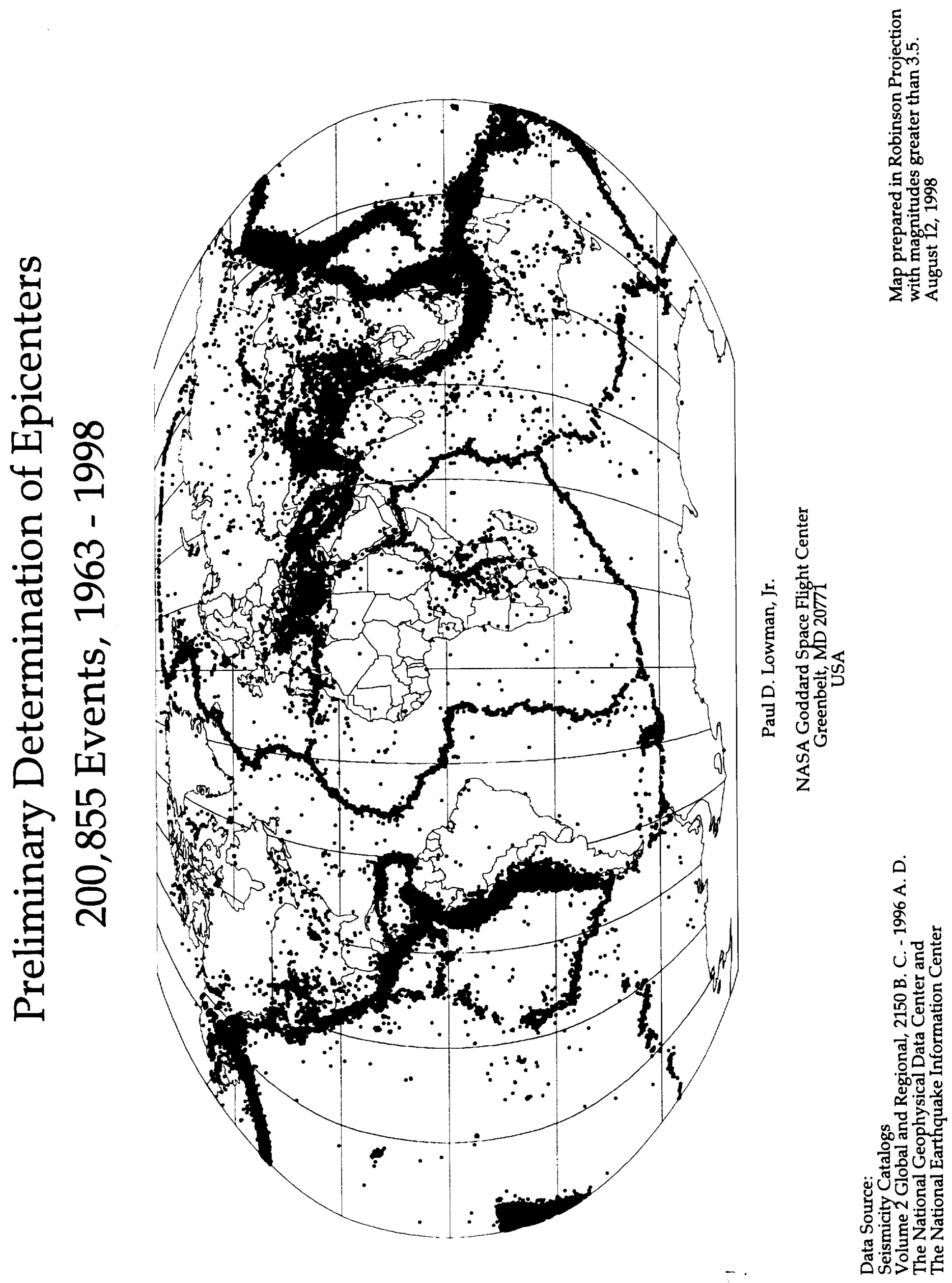




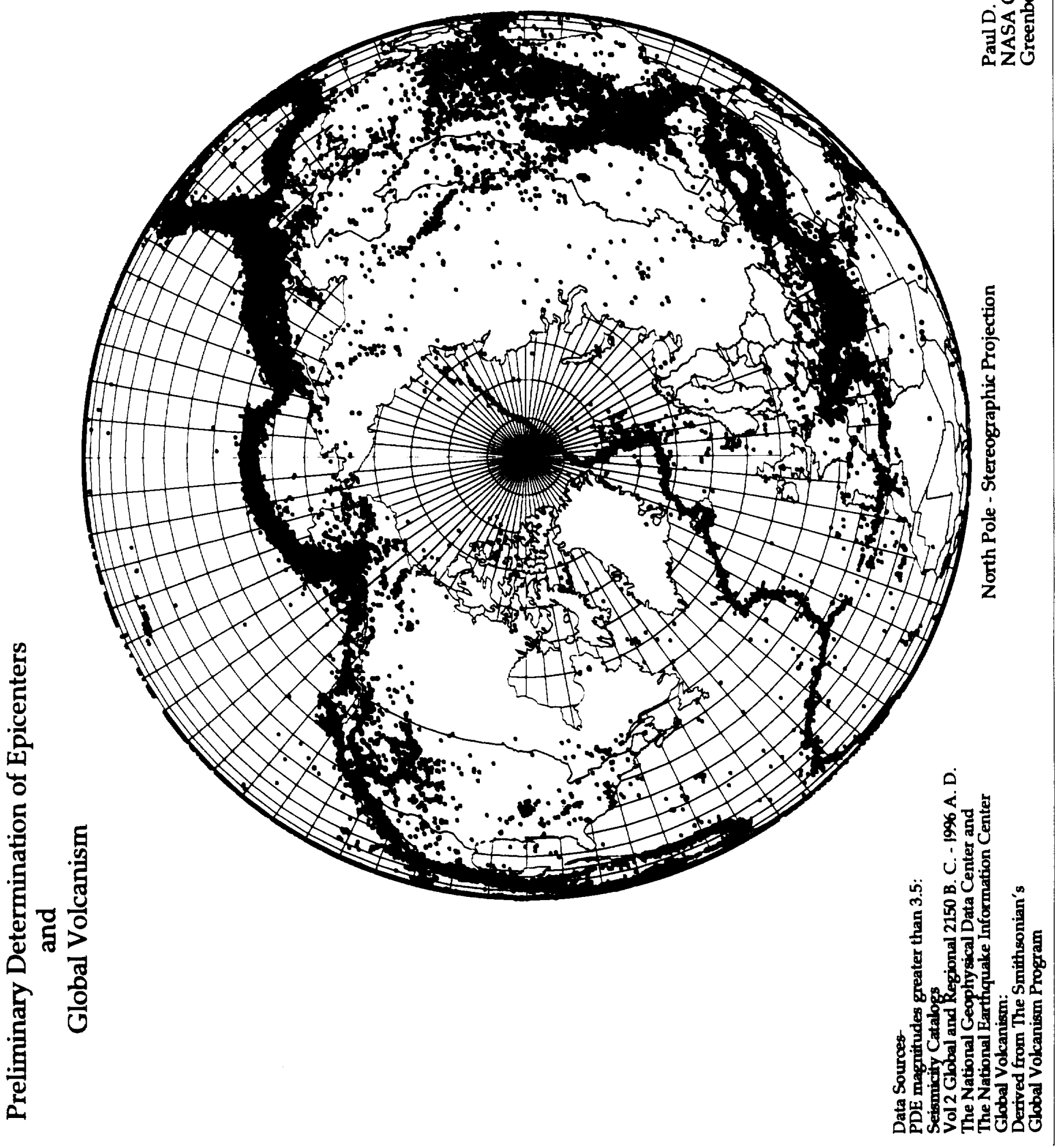




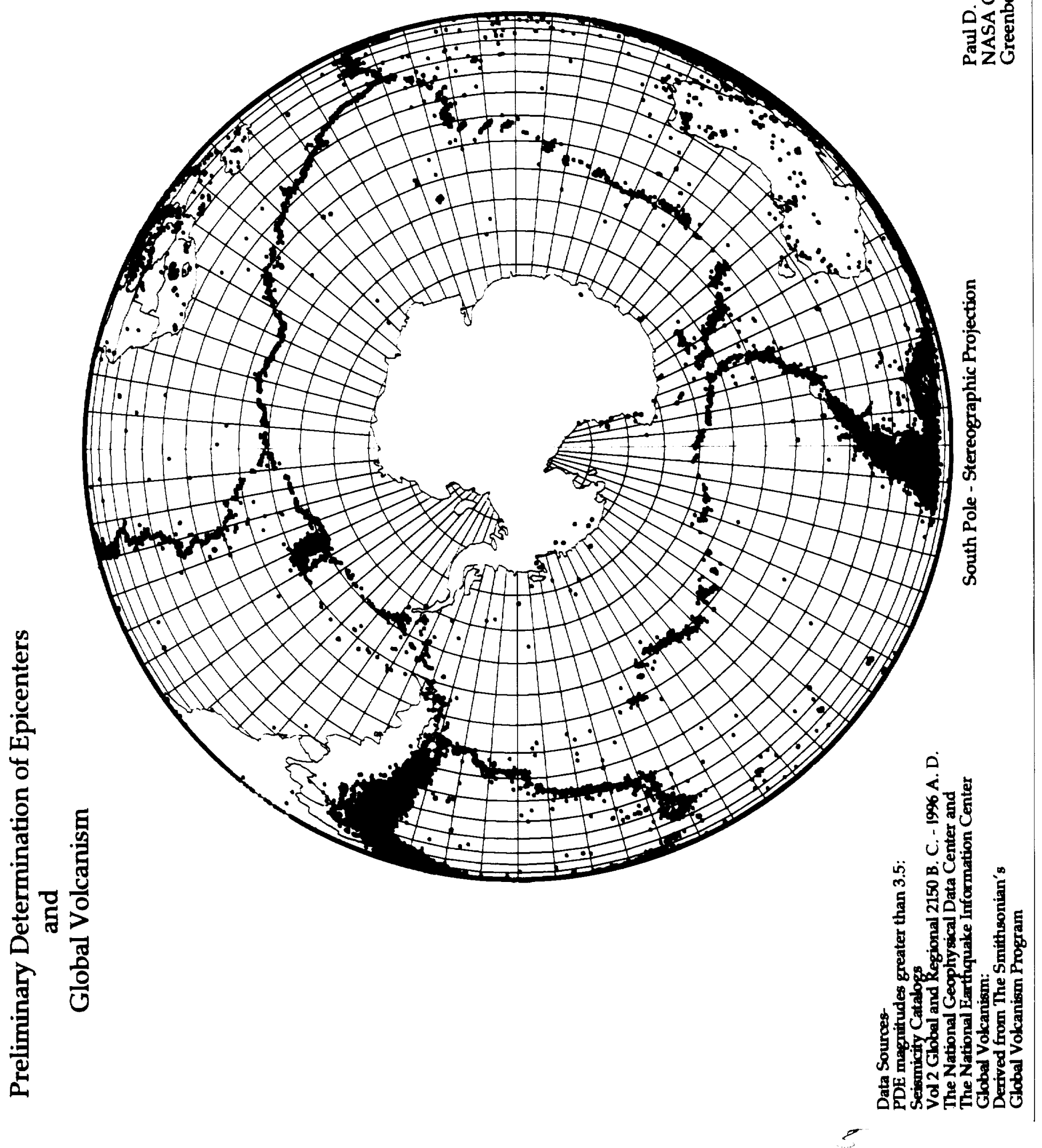




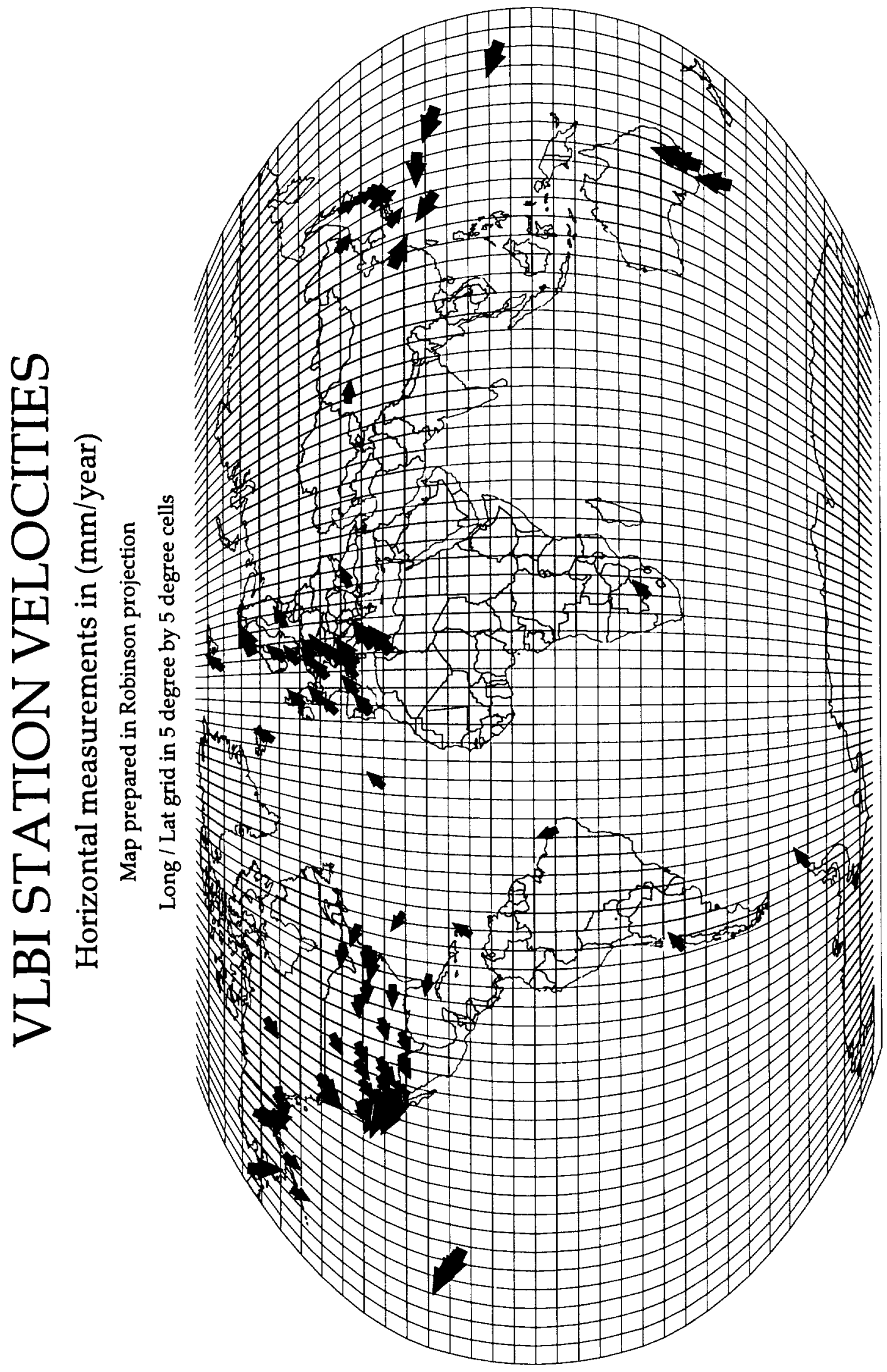

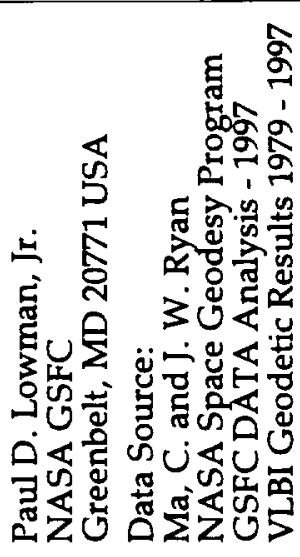

